\title{
Effect of Social Environment on Brand Recall in Sports Video Games
}

\author{
Ho Keat Leng, Nanyang Technological University, Singapore \\ (iD) https://orcid.org/0000-0002-7349-6540 \\ Ibrahim Mohamad Rozmand, St Joseph's Institution, Singapore \\ Yu Hong Low, River Valley High School, Singapore \\ Yi Xian Philip Phua, Nanyang Technological University, Singapore
}

\begin{abstract}
Studies have shown that in-game advertisements can be effective. However, these studies typically examine single player scenarios. This study aimed to investigate the effects of social dynamics on brand awareness of in-game advertisements in sports video games. Two studies were conducted with soccer and basketball simulation games. In each study, participants were split into two groups where they either played against a computer-controlled opponent or against another player. For both studies, independent-samples t-tests were conducted to compare the recall rates between both groups. Both studies showed similar findings where respondents in the single player group reported higher recall and recognition rates when compared to respondents in the multi-player group. These findings suggest that the social environment can affect the effectiveness of in-game advertisements.
\end{abstract}

\section{KEYWORDS}

Advertising, Brand Awareness, Experiment, FIFA 18, NBA 2K19, Recall, Recognition, Sponsorship

\section{INTRODUCTION}

The computer and video game business is a major industry. In 2018, video game sales in the United States exceeded US $\$ 43.4$ billion. More than 160 million adults in the United States alone play video games. In addition, three-quarters of all Americans have at least one gamer in their household (Entertainment Software Association, 2019). While gamers come from all age groups, they generally belong to younger age groups with an average age of about 33 years (Entertainment Software Association, 2019). Consequently, many organisations have viewed product placements in video games or in-game advertisements as a viable new platform in marketing communications. This is especially so with organisations keen to access the younger demographic segment of the market (Chaney, Lin, \& Chaney, 2004; Cianfrone, Trail, Zhang, \& Lutz, 2008; Clavio, Kraft, \& Pedersen, 2009; Leng, Quah, \& Zainuddin, 2010).

Sports video games are popular with gamers (Crawford \& Gosling, 2009). They are regularly listed among the top best-selling games in the United States. In 2018, basketball simulation game NBA 
2K19 and American football simulation game Madden NFL 19 were listed as the $3^{\text {rd }}$ and $4^{\text {th }}$ best-selling titles for the year. FIFA 19, a soccer simulation game, came in at $14^{\text {th }}$ place. The combined sports and racing game genres also accounted for $16.9 \%$ of the video game market in 2018. This was just behind action games (26.9\%) and shooter games (20.9\%) (Entertainment Software Association, 2019).

The use of product placement or in-game advertisements in sports video games is acceptable to gamers. As sponsored brands are commonly found within actual sports competitions and venues, the appearance of such advertisements in games can elevate the realism of the game. Hence, in-game advertisements allow organisations to deliver their promotional messages effectively (Cianfrone et al., 2008; Clavio et al., 2009; M. S. Kim \& McClung, 2010; Nelson, Keum, \& Yaros, 2004; Nichols, Farrand, Rowley, \& Avery, 2006).

There have been many studies conducted to examine the effectiveness of in-game advertisements. Specifically, the studies have examined the rate of brand recall and recognition in sports video games (Cianfrone et al., 2008; Dardis, Schmierbach, \& Limperos, 2012; Glass, 2007; Y. Kim \& Leng, 2017). Many of these studies have examined single player scenarios. However, the presence of other gamers is a central component in playing games (Sweetser, Johnson, \& Wyeth, 2012; Sweetser \& Wyeth, 2005). A recent industry survey found that $63 \%$ of gamers in the United States played with other players (Entertainment Software Association, 2019). As such, it is necessary to examine whether the effectiveness of in-game advertisements is affected by the social environment when the game is played in the presence of other gamers.

\section{LITERATURE REVIEW}

Balasubramanian (1994) defined product placement as a paid product message aimed at influencing audiences via the planned and unobtrusive entry of a branded product into a movie or television programme. While product placement was first introduced in other media, it eventually made its way into video games as in-game advertisements. Game developers realised that brand owners will be willing to pay to have their brands featured in their games, especially when the games appeal to the same target market as the brand (Nichols et al., 2006).

As in-game advertisements became a staple in marketing communications, there has been many studies conducted to examine its effectiveness. Many of these studies have focused on brand recall and recognition. In general, the studies have concluded that the rate of brand recall and recognition can be lower when compared to other media (Y. Kim, Walsh, \& Ross, 2008). However, the rate of recall can also be raised by making the brand more prominent in the game or through repeated exposure (Chaney et al., 2004; Dardis et al., 2012; Y. Kim \& Leng, 2017; M. Lee \& Faber, 2007; Leng et al., 2010; Nelson, 2002; Schneider \& Cornwell, 2005; Yang \& Wang, 2008).

Lang (2000) has suggested that people are information processors. According to the Limited Capacity Model of Mediated Message Processing, a person's ability to process information is limited. When a person allocates more cognitive resource to a task, it inevitably means that less cognitive resource can be allocated to other tasks. As such, some studies have found that gamers who are highly involved when playing games are likely to have lower rates of recall and recognition of ingame advertisements (Chaney et al., 2004; Herrewijn \& Poels, 2013; M. Lee \& Faber, 2007; Yoo \& Peña, 2011).

This also explains why several studies have found that familiar brands are more likely to be recalled when compared to unfamiliar brands (Y. Kim \& Leng, 2017; Leng et al., 2010; Schneider $\&$ Cornwell, 2005). Familiar brands already exist in the minds of gamers. Hence, they require less cognitive resource to process the brands due to perceptual fluency (Acar, 2007). Consequently, gamers are more likely to recall them.

Interestingly, brands that are irrelevant to the game can also lead to higher rates of recall and recognition. This is because gamers do not expect such brands to appear in the game and are 
intrigued by them. As a result, they dedicate more cognitive resources to try to understand why the brand is placed in the game. For example, in a car racing game, gamers do not expect to see brands of pet food as they are not related to the sport. However, they were found to be recalled at a higher rate when compared to brands in product categories related to car racing such as cars, oil and tyres (Balasubramanian, 1994; M. Lee \& Faber, 2007; Törn \& Dahlén, 2008). This does not mean that advertisers should start placing in-game advertisements in unrelated games as extremely incongruent in-game advertising can reduce the realism of the game and annoy gamers (Lewis \& Porter, 2010).

The studies on in-game advertisements have examined many variables affecting brand recall. One area that has been examined to a lesser extent is the effect of gamer experience on brand recall (Leng \& Pyun, 2018). Gamer experience consists of various elements including positive and negative emotions. It has been suggested that a higher level of positive emotional experiences and a lower level of negative emotional experiences can affect the processing and evaluation of in-game advertisements (Herrewijn \& Poels, 2013). Playing sports video games is a form of hedonic consumption behavior as gamers not only enjoy the game but are able to fulfill their sporting fantasies (Y. Kim \& Ross, 2006; Kwak, Clavio, Eagleman, \& Kim, 2010; S. Lee, Seo, \& Green, 2013). Hence, sports video gamers are more likely to experience positive emotions.

However, an individual's gaming experience extends beyond engagement with a game. It is also about social interaction or the presence of others while playing the game (Bowman, Weber, Tamborini, \& Sherry, 2013; Sweetser et al., 2012; Sweetser \& Wyeth, 2005). Models of gamer experience have generally incorporated this element in examining gamer experience (IJsselsteijn, De Kort, \& Poels, 2013). However, there are only few studies conducted on the social element in games. These studies have suggested that co-play may enhance performance in the game (Bowman et al., 2013) and lead to better parent-child relationships (Coyne, Padilla-Walker, Stockdale, \& Day, 2011; Wang, Taylor, \& Sun, 2018). Studies on in-game advertisements have generally not examined this social environment as they are usually conducted using single player scenarios. Hence, there is a need to examine the effect of the social environment on brand recall in sports video games.

Research Question: Is there any difference in brand recall rates between gamers in single player versus multi-player games?

\section{METHOD}

Two studies were conducted which are described in detail below. In each study, a different sports video game was used. This was to examine if findings were consistent across video games of different sports. Two measures of brand awareness were used in the studies. In unaided brand recall, respondents were asked to list the brands that appeared in the game. In brand recognition, respondents were given a list of brands and asked to identify brands that appeared in the game. The list of brands include both brands that appeared in the game and brands that were from the same industry but did not appear in the game.

The study also collected data on gamer experience. Measures of Flow, Enjoyment and Negative Affect were adapted from an earlier study (Leng \& Pyun, 2018). Flow was measured by a 3-item scale while both Enjoyment and Negative Affect were measured by 4-item scales. The scales had good internal consistency. Cronbach alpha coefficients for Flow, Enjoyment and Negative Affect for Study 1 were $.96, .98$ and .75 respectively. Cronbach alpha coefficients for Flow, Enjoyment and Negative Affect for Study 2 were .83, .90 and .73 respectively. The items are detailed in Table 1. 
Table 1. Items to Measure Flow, Enjoyment and Negative Affect

\begin{tabular}{|l|l|}
\hline \multicolumn{1}{|c|}{ Factor } & \\
\hline \multirow{4}{*}{ Flow } & Item \\
\cline { 2 - 3 } & I felt completely absorbed in the game. \\
\cline { 2 - 3 } Enjoyment & I lost track of time playing this game. \\
\hline \multirow{5}{*}{$\begin{array}{l}\text { Negative } \\
\text { Affect }\end{array}$} & The game was fun. \\
\cline { 2 - 2 } & I enjoyed the game. \\
\cline { 2 - 2 } & This is a good game. \\
\cline { 2 - 2 } & Playing the game was a pleasurable experience. \\
\hline & The game was frustrating. \\
\cline { 2 - 2 } & I was irritated with many aspects of the game. \\
\cline { 2 - 2 } & The game was boring. \\
\cline { 2 - 2 } & The game was a disappointment. \\
\hline
\end{tabular}

\section{STUDY 1 FIFA 18}

FIFA 18, a football simulation video game was selected as the sports video game for this study. Students from a tertiary institution were solicited to participate in the study. 19 participants with a mean of 16.9 years of age participated in the study. 10 of the participants were of male gender $(53 \%)$.

Participants were randomly assigned to either Experimental Group $1(n=9)$ where they played against the computer i.e. single player or Experimental Group $2(n=10)$ where they played against each other i.e. multi-player. Participants in Experimental Group 1 thus played the game without communicating with other people while the participants in Experimental Group 2 were able to communicate with each other while playing the game.

The experiment was conducted in a room to reduce distraction for the participants. As much as possible, experimental conditions were kept the same for all respondents. These include room lighting, size of monitor, distance from the monitor, game controllers, etc.

At the beginning of the study, participants were informed that they were to play a sports video game and complete a survey. Game settings were also the same and pre-selected for all participants. Participants played with the teams Leicester City and Bournemouth for a duration of 4 minutes in King Power Stadium. Participants in Experimental Group 1 played as Leicester City against Bournemouth while participants in Experimental Group 2 played either as Leicester City or Bournemouth against each other. The weather was set as Spring and the time of the match was set at $9 \mathrm{pm}$. This was to prevent the presence of shadows created by the game's engine for matches set in the day, which may obscure the visibility of the sponsors in the game. For the group that played against the computer, the difficulty was set to 'Professional', which was a mid-level of difficulty for the game.

For this study, measures of recall and recognition of sponsors were based on the advertising boards that appear along the perimeter of the virtual football field during the game. The brands that appeared during the game were thus the same for all the matches as they were determined by the teams selected. The six brands that appeared on these boards were Standard Chartered Bank, King Power, Puma, AirAsia, Amazing Thailand and DHL. 


\section{STUDY 2 NBA 2 K19}

In this study, the game selected was a basketball simulation game, NBA 2K19. 40 respondents were recruited and randomly distributed evenly into Experimental Group 1 and Experimental Group 2. Respondents in Experimental Group $1(n=20)$ played the game as a single player against the computer while respondents in Experimental Group $2(n=20)$ played against each other in a multi-player game. The mean age of the respondents was 16.3 years of age. 28 respondents $(70 \%)$ were of male gender.

Like Study 1, the experiment was conducted in a room with the same conditions for all respondents. Respondents played four quarters of four minutes each. The total time spent on the game is thus 16 minutes. The two teams selected for this experiment were Orlando Magic and Utah Jazz. The decision to use these two less popular NBA teams among Singapore fans was to reduce the probability that respondents might recall team sponsors due to their pre-existing knowledge of the teams in real life. Respondents in Experimental Group 1 in the single player game played as the Orlando Magic while respondents in Experimental Group 2 in the multi-player game played as either of the teams. Similar to the previous study, the in-game settings were kept the same for all respondents. The difficulty level was set to Pro for all respondents as this was the recommended difficulty level for both new and experienced players.

At the end of the game, respondents completed an online survey instrument which measured the rate of unaided brand recall, brand recognition and gamer experience. There were 11 brands that appeared on the advertising boards in the game. These were Gatorade, Spalding, Beats, State Farm, Tissot, Foot Locker, New Era, Reese's, Ruffles, Disney and Qualtrics Cancer Charity. For brand recognition, respondents were asked to select brands that appeared in the game from a list of 22 brands i.e. 11 brands were added to the list of brands that appeared in the game. Similar to the prior study, the brands added were similar to the actual brands that appeared. For example, Doritos was added as it was in the same product category as Ruffles.

\section{FINDINGS AND ANALYSIS}

In both studies, the data collected via the online survey were analysed using IBM Statistical Packages for the Social Sciences (SPSS) v23. For both studies, a series of independent t-tests were conducted to compare the level of brand awareness of participants across groups. These are detailed as below.

\section{Study 1 FIFA 18}

An independent-samples t-test was conducted to compare the recall rates between Experimental Groups 1 and 2. There was a significant difference in the recall rate with respondents in Experimental Group 1 reporting a higher unaided recall rate $(\mathrm{M}=.89, \mathrm{SD}=1.45)$ when compared to respondents in Experimental Group $2(\mathrm{M}=.10, \mathrm{SD}=.32 ; t(9)=1.60, p=.07)$. The results showed that respondents in the single player group were able to recall more brands than respondents in the multi-player group. This suggests that the opportunity to communicate with each other can negatively affect the brand recall rate.

An independent-samples t-test was also conducted to compare the recognition rates for Experimental Groups 1 and 2. Again, there was a significant difference in the recognition rate with respondents in Experimental Group 1 reporting a higher recognition rate $(\mathrm{M}=2.78, \mathrm{SD}=1.79)$ when compared to respondents in Experimental Group $2(\mathrm{M}=.60, \mathrm{SD}=.52 ; t(9)=3.53, p<.01)$. These are detailed in Table 2.

The results showed that respondents in the single player group were able to recognise more brands than respondents in the multi-player group. This supports the above finding that the opportunity to communicate with each other can negatively affect the brand recall rate. 
Table 2. Brand Recall and Recognition across single and multi-player groups

\begin{tabular}{|c|c|c|c|}
\hline & M (SD) & $t$-Stat & $p$ value (one-tail) \\
\hline \multicolumn{4}{|l|}{ Study 1 Brand Unaided Recall } \\
\hline $\begin{array}{l}\text { Experimental Group } 1 \text { Single } \text { Player }^{\mathbf{a}} \\
\text { Experimental Group } 2 \text { Multi-Player }\end{array}$ & $\begin{array}{l}0.89(1.45) \\
0.10(.32)\end{array}$ & 1.60 & .07 \\
\hline \multicolumn{4}{|l|}{ Study 1 Brand Recognition } \\
\hline $\begin{array}{l}\text { Experimental Group } 1 \text { Single Player }{ }^{\mathbf{a}} \\
\text { Experimental Group } 2 \text { Multi-Player }{ }^{\mathrm{b}}\end{array}$ & $\begin{array}{l}2.78(1.79) \\
.60(.52)\end{array}$ & 3.53 & $<.01$ \\
\hline \multicolumn{4}{|l|}{ Study 2 Brand Unaided Recall } \\
\hline $\begin{array}{l}\text { Experimental Group } 1 \text { Single Player } \\
\text { Experimental Group } 2 \text { Multi-Player }\end{array}$ & $\begin{array}{l}1.20(1.47) \\
0.65(.93)\end{array}$ & 1.41 & .08 \\
\hline \multicolumn{4}{|l|}{ Study 2 Brand Recognition } \\
\hline $\begin{array}{l}\text { Experimental Group } 1 \text { Single Player } \\
\text { Experimental Group } 2 \text { Multi-Player }\end{array}$ & $\begin{array}{l}2.65(2.16) \\
2.00(1.89)\end{array}$ & 1.01 & .16 \\
\hline
\end{tabular}

${ }^{\mathrm{a}} n=9 ;{ }^{\mathrm{b}} n=10 ;{ }^{\mathrm{c}} n=20 ;{ }^{\mathrm{d}} n=20$

\section{Study 2 NBA 2 K19}

An independent-samples t-test was conducted to compare the recall rates between Experimental Groups 1 and 2. There was a significant difference in the recall rate with respondents in Experimental Group 1 reporting a higher unaided recall rate $(\mathrm{M}=1.20, \mathrm{SD}=1.47)$ when compared to respondents in Experimental Group $2(\mathrm{M}=.65, \mathrm{SD}=.93 ; t(32)=1.41, p=.08)$. The results again showed that respondents in the single player group were able to recall more brands than respondents in the multi-player group.

An independent-samples t-test was conducted to compare the recognition rates for Experimental Groups 1 and 2. However, while respondents in Experimental Group 1 reported a higher recognition rate $(\mathrm{M}=2.65, \mathrm{SD}=2.16)$ when compared to respondents in Experimental Group $2(\mathrm{M}=2.00, \mathrm{SD}$ $=1.89)$, it did not reach statistical significance at $\alpha=.10(t(37)=1.69, p=.16)$. These are detailed in Table 2.

An independent-samples t-test was conducted to compare for differences in Flow, Enjoyment and Negative Affect across experimental groups in both studies. In Study 1, there was a significant difference in Flow $\left(\mathrm{M}_{\text {single player }}=2.96, \mathrm{SD}_{\text {single player }}=1.27 ; \mathrm{M}_{\text {multi-player }}=4.73, \mathrm{SD}_{\text {multi-player }}=.44 ; t(10)\right.$ $=3.96, p<.01)$ and Enjoyment $\left(\mathrm{M}_{\text {single player }}=3.38, \mathrm{SD}_{\text {single player }}=1.44 ; \mathrm{M}_{\text {multi-player }}=4.53, \mathrm{SD}_{\text {multi-player }}\right.$ $=.71 ; t(10)=2.07, p=.07)$. Respondents in the multi-player group reported higher levels of flow and enjoyment when compared to respondents in the single player group. However, there was no significant difference in Negative Affect $\left(\mathrm{M}_{\text {single player }}=2.61, \mathrm{SD}_{\text {single player }}=.76 ; \mathrm{M}_{\text {multi-player }}=2.23\right.$, $\left.\mathrm{SD}_{\text {multi-player }}=.89 ; t(17)=1.01, p>.10\right)$.

In Study 2, there was no significant difference in Flow $\left(\mathrm{M}_{\text {single player }}=3.70, \mathrm{SD}_{\text {single player }}=.82\right.$; $\left.\mathrm{M}_{\text {multi-player }}=3.60, \mathrm{SD}_{\text {multi-player }}=1.20 ; t(38)=.31, p>.10\right)$, Enjoyment $\left(\mathrm{M}_{\text {single player }}=4.20, \mathrm{SD}_{\text {single player }}\right.$ $\left.=.67 ; \mathrm{M}_{\text {multi-player }}=4.25, \mathrm{SD}_{\text {multi-player }}=.97 ; t(38)=.19, p>.10\right)$ and Negative Affect $\left(\mathrm{M}_{\text {single player }}=\right.$ $\left.2.21, \mathrm{SD}_{\text {single player }}=.78 ; \mathrm{M}_{\text {multi-player }}=2.32, \mathrm{SD}_{\text {multi-player }}=.85 ; t(38)=.44, p>.10\right)$. This suggests that there are differences across games. In some games, multi-player games are more likely to result in a flow state and higher levels of enjoyment but this is not universal across games.

Further analysis was conducted using Spearman rho to examine the relationships between Recall, Recognition, Flow, Enjoyment and Negative Affect. Positive, moderate to strong relationships between recall and recognition were found for three groups. This was expected as many earlier studies have found strong, positive correlation between recall and recognition rates. Respondents who are able to recall a larger number of sponsors are more likely to recognise a larger number of sponsors as 
Table 3. Correlation between respondents in different experimental groups and studies using Spearman rho

\begin{tabular}{|c|c|c|c|c|c|c|}
\hline & & 1 & 2 & 3 & 4 & 5 \\
\hline \multirow{5}{*}{ Study 1 Single Player } & 1 Recall & 1.00 & $.85^{* *}$ & -.08 & -.11 & .51 \\
\hline & 2 Recognition & & 1.00 & .10 & -.01 & .50 \\
\hline & 3 Flow & & & 1.00 & $.70^{*}$ & -.31 \\
\hline & 4 Enjoyment & & & & 1.00 & $-.70 *$ \\
\hline & 5 Negative Affect & & & & & 1.00 \\
\hline \multirow{5}{*}{ Study 1 Multi-Player } & 1 Recall & 1.00 & .27 & .22 & .31 & -.18 \\
\hline & 2 Recognition & & 1.00 & -.18 & .15 & .04 \\
\hline & 3 Flow & & & 1.00 & $.81^{* *}$ & -.29 \\
\hline & 4 Enjoyment & & & & 1.00 & .03 \\
\hline & 5 Negative Affect & & & & & 1.00 \\
\hline \multirow{5}{*}{ Study 2 Single Player } & 1 Recall & 1.00 & $.65^{* *}$ & .09 & -.08 & -.35 \\
\hline & 2 Recognition & & 1.00 & .02 & .02 & -.28 \\
\hline & 3 Flow & & & 1.00 & .33 & -.02 \\
\hline & 4 Enjoyment & & & & 1.00 & $-.56 * *$ \\
\hline & 5 Negative Affect & & & & & 1.00 \\
\hline \multirow{5}{*}{ Study 2 Multi-Player } & 1 Recall & 1.00 & $.51 *$ & -.33 & -.17 & .03 \\
\hline & 2 Recognition & & 1.00 & -.17 & -.21 & .03 \\
\hline & 3 Flow & & & 1.00 & $.75^{* *}$ & -.18 \\
\hline & 4 Enjoyment & & & & 1.00 & $-.55^{*}$ \\
\hline & 5 Negative Affect & & & & & 1.00 \\
\hline
\end{tabular}

${ }^{*} p<.05,{ }^{* *} p<.01$

well. However, in the group of multi-players in Study 1, while the relationship between recall and recognition was positive, it did not reach statistical significance.

There were no significant relationships between Recall and Recognition with Flow, Enjoyment and Negative Effect across all groups. Hence, this did not support the suggestion that recall and recognition rates were affected by positive emotions (Herrewijn \& Poels, 2013). However, positive and strong relationships were found between Flow and Enjoyment in three groups. In addition, negative and strong relationships were found between Enjoyment and Negative Affect for three groups. This is to be expected as the experience of a flow state is often described to be a positive experience. In addition, it is expected that positive and negative experiences of the games should have a negative, strong relationship with each other. This is detailed in Table 3.

\section{DISCUSSION}

The findings from the first study suggest that there were differences between the groups in terms of brand recall and recognition. Participants who were tasked to play the video game against the computer reported both higher brand recall and brand recognition rates as compared to participants who played against another person. This could be attributed in part to the Limited Capacity Model of Mediated Message Processing (Lang, 2000). As the participants in the multi-player group were in a heightened social setting as compared to participants in the single player group, it stands to reason 
that the social element that was present in that condition could have caused the individual to allocate cognitive resources towards it. Gamers in multi-player settings may be more likely to converse with other players and be distracted from the screen. As such, less attention may be placed on the game as compared to gamers in the single player group.

While Study 2 only found significant difference in brand recall and not brand recognition, the findings were still similar to Study 1. Participants who were assigned to play a single player game recorded higher levels of brand awareness in terms of brand recall and brand recognition rates. This suggests that while the presence of others in the gaming environment can affect recall rate, this may also be dependent on the type of games played.

Further analysis on gamer experience support the existence of difference between games. In FIFA 18, respondents in the multi-player group reported higher levels of flow and enjoyment when compared to respondents in the single player group. However, there was no difference between multiplayer and single player respondents in Study 2 with the NBA 2K19 game.

Interestingly, the findings did not show any significant relationships between brand awareness and measures of gamer experience as postulated in the literature. While some relationships were expected eg the positive relationship between flow and enjoyment, the findings also suggested that the relationships were not universal across all groups. These suggest that the relationships between the variables may be more complex.

\section{CONCLUSION}

This study aimed to investigate the effect of the social environment on brand awareness of in-game advertisements in sports video games. It found that respondents in single player games are more aware of brands when compared to respondents in multi-player games. These findings suggest that game developers and marketers should examine ways to attract gamers' attention particularly for multi-player games. In addition, the findings suggest that there are also differences across games. Hence, game developers and marketers need to adapt their strategies across games.

There were several limitations for this study. The first limitation was that the individual skill level of the participants was not taken into consideration. This could have influenced an individual's cognitive capacity to process advertising boards that appear in the game. This is especially so for novice players who have to devote cognitive resources toward understanding and learning the controls of the game, and thus be unable to notice other stimuli presented to them. Future research could investigate this further by grouping the participants based on their skill level.

Another limitation of this study was that it did not account for differences in social dynamics between participants in the multi-player group. Social dynamics between games could affect the experiences of the respondents. This was evident in observations of the second experimental group, where there were differing levels of interaction between the participants. Some participants played in complete silence without communicating with each other, while others communicated actively throughout the session. This suggests that social dynamics could affect the experiences between respondents within the group. This will need to be examined in future studies.

The final limitation is with regard to the nature of co-play adopted in this study. For both studies, the co-play element was implemented in a setting where individuals were pitted against one another, as opposed to a cooperative setting. This could be a factor that should be examined especially in consideration of the social dynamics highlighted above. As such, future research can consider varying the task orientation within or between games, where participants are placed in a setting that fosters cooperation as well as competition. 


\section{ACKNOWLEDGMENT}

We would like to acknowledge the funding support for this study from Nanyang Technological University under the Nanyang Research Program.

\section{FUNDING AGENCY}

Open Access Funding for this article has been provided by IGI Global. 


\section{REFERENCES}

Acar, A. (2007). Testing the effects of incidental advertising exposure in online gaming environments. Journal of Interactive Advertising, 8(1), 45-56. doi:10.1080/15252019.2007.10722136

Balasubramanian, S. K. (1994). Beyond advertising and publicity: Hybrid messages and public policy issues. Journal of Advertising, 23(4), 29-46. doi:10.1080/00913367.1943.10673457

Bowman, N. D., Weber, R., Tamborini, R., \& Sherry, J. (2013). Facilitating game play: How others affect performance at and enjoyment of video games. Media Psychology, 16(1), 39-64. doi:10.1080/15213269.201 2.742360

Chaney, I. M., Lin, K.-H., \& Chaney, J. (2004). The effect of billboards within the gaming environment. Journal of Interactive Advertising, 5(1), 54-69. doi:10.1080/15252019.2004.10722092

Cianfrone, B. A., Trail, G. T., Zhang, J. J., \& Lutz, R. J. (2008). Effectiveness of in-game advertisements in sport video games: An experimental inquiry on current gamers. International Journal of Sport Communication, 1(2), 195-218. doi:10.1123/ijsc.1.2.195

Clavio, G., Kraft, P. M., \& Pedersen, P. M. (2009). Communicating with consumers through video games: An analysis of brand development within the video gaming segment of the sports industry. International Journal of Sports Marketing \& Sponsorship, 10(2), 39-52. doi:10.1108/JSMS-10-02-2009-B005

Coyne, S. M., Padilla-Walker, L. M., Stockdale, L., \& Day, R. D. (2011). Game on... girls: Associations between co-playing video games and adolescent behavioral and family outcomes. The Journal of Adolescent Health, 49(2), 160-165. doi:10.1016/j.jadohealth.2010.11.249 PMID:21783048

Crawford, G., \& Gosling, V. (2009). More than a game: Sports-themed video games \& player narratives. Sociology of Sport Journal, 26(1), 50-66. doi:10.1123/ssj.26.1.50

Dardis, F. E., Schmierbach, M., \& Limperos, A. M. (2012). The impact of game customization and control mechanisms on recall of integral and peripheral brand placements in videogames. Journal of Interactive Advertising, 12(2), 1-12. doi:10.1080/15252019.2012.10722192

Entertainment Software Association. (2019). Essential facts about the computer and video game industry. Author.

Glass, Z. (2007). The effectiveness of product placement in video games. Journal of Interactive Advertising, 8(1), 23-32. doi:10.1080/15252019.2007.10722134

Herrewijn, L., \& Poels, K. (2013). Putting brands into play: How game difficulty and player experiences influence the effectiveness of in-game advertising. International Journal of Advertising, 32(1), 17-44. doi:10.2501/IJA32-1-017-044

IJsselsteijn, W., De Kort, Y., \& Poels, K. (2013). The game experience questionnaire. Technische Universiteit Eindhoven.

Kim, M. S., \& McClung, S. R. (2010). Acceptability and ethics of product placement in sport video games. Journal of Promotion Management, 16(4), 411-427. doi:10.1080/10496491003591386

Kim, Y., \& Leng, H. K. (2017). Effectiveness of in-game advertisement: An examination of repetition effect, brand familiarity and the relationship between gaming skills and advertising execution. Journal of Global Sport Management, 2(1), 42-64. doi:10.1080/24704067.2017.1281714

Kim, Y., \& Ross, S. D. (2006). An exploration of motives in sport video gaming. International Journal of Sports Marketing \& Sponsorship, 8(1), 28-40. doi:10.1108/IJSMS-08-01-2006-B006

Kim, Y., Walsh, P., \& Ross, S. D. (2008). An examination of the psychological and consumptive behaviors of sport video gamers. Sport Marketing Quarterly, 17(1), 44-53.

Kwak, D. H., Clavio, G. E., Eagleman, A. N., \& Kim, K. T. (2010). Exploring the antecedents and consequences of personalizing sport video game experiences. Sport Marketing Quarterly, 19(4).

Lang, A. (2000). The limited capacity model of mediated message processing. Journal of Communication, 50(1), 46-70. doi:10.1111/j.1460-2466.2000.tb02833.x 
Lee, M., \& Faber, R. J. (2007). Effects of product placement in on-line games on brand memory: A perspective of the limited-capacity model of attention. Journal of Advertising, 36(4), 75-90. doi:10.2753/JOA0091-3367360406

Lee, S., Seo, W. J., \& Green, B. C. (2013). Understanding why people play fantasy sport: Development of the Fantasy Sport Motivation Inventory (FanSMI). European Sport Management Quarterly, 13(2), 166-199. doi: $10.1080 / 16184742.2012 .752855$

Leng, H. K., \& Pyun, D. Y. (2018). Development of a scale to measure gamer experiences in sport video games. International Journal of Sport Management and Marketing, 18(5), 417-429. doi:10.1504/IJSMM.2018.094348

Leng, H. K., Quah, S. L., \& Zainuddin, F. (2010). The Obama Effect: An Exploratory Study on Factors Affecting Brand Recall in Online Games. International Journal of Trade. Economics and Finance, 1(1), 1-5.

Lewis, B., \& Porter, L. (2010). In-game advertising effects: Examining player perceptions of advertising schema congruity in a massively multiplayer online role-playing game. Journal of Interactive Advertising, 10(2), 46-60. doi:10.1080/15252019.2010.10722169

Nelson, M. R. (2002). Recall of brand placements in computer/video games. Journal of Advertising Research, 42(2), 80-92. doi:10.2501/JAR-42-2-80-92

Nelson, M. R., Keum, H., \& Yaros, R. A. (2004). Advertainment or adcreep game players' attitudes toward advertising and product placement in computer games. Journal of Interactive Advertising, 5(1), 3-21. doi:10. $1080 / 15252019.2004 .10722090$

Nichols, D., Farrand, T., Rowley, T., \& Avery, M. (2006). Brands and Gaming: The Computer Gaming Phenomenon and the Impact of Brands on Gaming. Palgrave Macmillan. doi:10.1057/9780230286573

Schneider, L. P., \& Cornwell, T. B. (2005). Cashing in on crashes via brand placement in computer games: The effects of experience and flow on memory. International Journal of Advertising, 24(3), 321-343. doi:10.1080 /02650487.2005.11072928

Sweetser, P., Johnson, D. M., \& Wyeth, P. (2012). Revisiting the GameFlow model with detailed heuristics. Journal: Creative Technologies, 2012(3).

Sweetser, P., \& Wyeth, P. (2005). GameFlow: A model for evaluating player enjoyment in games. Computers in Entertainment, 3(3), 3-3. doi:10.1145/1077246.1077253

Törn, F., \& Dahlén, M. (2008). Effects of brand incongruent advertising in competitive settings. European Advances in Consumer Research, 8, 234-239.

Wang, B., Taylor, L., \& Sun, Q. (2018). Families that play together stay together: Investigating family bonding through video games. New Media \& Society, 20(11), 4074-4094. doi:10.1177/1461444818767667

Yang, H. L., \& Wang, C. S. (2008). Product placement of computer games in cyberspace. Cyberpsychology \& Behavior, 11(4), 399-404. doi:10.1089/cpb.2007.0099 PMID:18721087

Yoo, S. C., \& Peña, J. (2011). Do Violent Video Games Impair The Effectiveness of In-Game Advertisements? The Impact of Gaming Environment on Brand Recall, Brand Attitude, and Purchase Intention. Cyberpsychology, Behavior, and Social Networking, 14(7-8), 439-446. doi:10.1089/cyber.2010.0031 PMID:21117975

Ibrahim Mohamad Rozmand studies at St Joseph's Institution and has undergone the Business Design Thinking modules for three years at secondary school level as well as undergone the Nanyang Research Programme under Nanyang Technology University (NTU) in the first and second year at junior college level.

Yu Hong Low is a student at River Valley High School, Singapore.

Yi Xian Philip Phua is a PhD Candidate specializing in Sports Marketing and Sponsorship. 